\title{
ИНВЕСТИЦИОННЫЙ ПОТЕНЦИАЛ ХОЗЯЙСТВУЮЩЕГО СУБЪЕКТА В СИСТЕМЕ ОСНОВНЫХ КАТЕГОРИЙ ИНВЕСТИЦИЙ
}

\begin{abstract}
АНнотАция. Активизация инвестиционных процессов является основным условием экономического развития хозяйствующих субъектов. Проблема привлечения инвестиций - одна из приоритетных задач, стоящая перед обществом. Из-за ограниченности ресурсов полностью удовлетворить потребность всех потенциальных реципиентов в инвестициях невозможно. Дефицит инвестиционных ресурсов приводит к увеличению уровня конкуренции на них, что объясняет необходимость предварительной оценки потенциальных объектов инвестирования. В науке выделяют различные понятия, термины, категории, с помощью которых становится возможным проанализировать и разработать мероприятия по регулированию инвестиционных процессов. В статье рассматриваются ключевые категории инвестиций, такие как «инвестиционный климат», «инвестиционная привлекательность», «инвестиционная активность» и «инвестиционный потенциал». Проводится анализ экономической сущности данных понятий. Обобщаются и дополняются мнения авторов, применяющих различные подходы к их определению. Выявляются сходства и отличия представленных категорий инвестиций, их взаимосвязь и взаимозависимость. Одним из обобщающих показателей, определяющих итоговое значение категорий «инвестиционный климат», «инвестиционная привлекательность» и «инвестиционная активность» выступает категория «инвестиционный потенциал». Чем выше инвестиционный потенциал, тем благоприятнее инвестиционный климат экономической системы, что соответственно повышает интенсивность инвестиционной деятельности.
\end{abstract}

КЛЮЧЕВЫЕ сЛОВА. Инвестиционный потенциал; инвестиционная деятельность; объект инвестирования; экономические ресурсы; инвестиционные риски; воспроизводство капитала; инвестиционный климат; инвестиционная привлекательность; инвестиционная активность.

ИНФОРМАЦИЯ О СТАТЬЕ. Дата поступления 5 мая 2016 г.; дата принятия к печати 27 мая 2016 г.; дата онлайн-размещения 26 сентября 2016 г.

I. Yu. Novikova

Baikal State University,

Irkutsk, Russian Federation

\section{INVESTMENT POTENTIAL OF THE ENTITY IN THE SYSTEM OF MAIN CATEGORIES OF INVESTMENTS}

\begin{abstract}
Activation of investment processes is the basic condition of economic development of economic entities. The problem of attracting investments is one of the priority tasks facing the society. Because of resource limitations, it is impossible to meet the needs of all potential recipients in investments. The deficit of investment resources results in increasing the completion level for them, which explains the necessity of preliminary assessment of potential investment objects. The science identifies various concepts, terms, categories which make it possible to analyze and develop the activities on regulating investment processes. The limited investment resources leads to an increase in the level of competition on them, which explains the need for preliminary assessment of potential investment objects. In science distinguish various concepts, terms, categories, by which it becomes possible to perform and to develop measures on regulation of investment processes. The article considers the key categories of investments, such as «investment climate», «investment attractiveness», «investment performance» and «investment potential». It makes an analysis of the economic essence of these concepts, generalizes and complements the opinions of the authors who use different approaches to their definition. It identifies similarities and differences of the represented investment categories, their interrelation and interdependence. One of the resumptive indicators determining the final value of the
\end{abstract}

(с) И. Ю. Новикова, 2016

\section{Baikal Research Journal}


categories «investment climate» «investment attractiveness» and «investment performance» is the category of «investment potential». The higher the investment potential, the more favorable investment climate of the economic system is, which subsequently increases the intensity of investment performance.

KEYWORDS. Investment potential; investment activity; investment; economic resources; investment risks; the reproduction of capital; investment climate; investment attractiveness; investment activity.

ARTICLE INFO. Received May 5, 2016; accepted May 27, 2016; available online September $26,2016$.

Ключевым условием экономического развития любого хозяйствующего субъекта на различных экономических уровнях является активизация инвестиционного процесса. Инвестиции необходимы для модернизации экономики, интенсификации развития экономических систем. Проблема привлечения инвестиций - одна из приоритетных задач, стоящая перед обществом.

Полностью удовлетворить потребность в инвестициях невозможно. В этом случае необходима оценка потенциальных объектов инвестирования. Выбор, стоящий перед инвесторами, заключается в определении наиболее успешных перспектив развития объекта инвестирования, а также в максимально эффективной отдаче от вложенных ресурсов.

Учитывая сложность управления инвестиционными процессами, оценки объектов инвестирования, выявления и анализа факторов, оказывающих влияние на объекты инвестирования, в науке выделяют понятия, термины, категории, с помощью которых становится возможным проанализировать и разработать мероприятия по регулированию инвестиционных процессов. $\mathcal{K}$ основным понятиям относят: инвестиционный климат, инвестиционная привлекательность, инвестиционная активность, инвестиционный потенциал.

Данные экономические категории в настоящее время регулярно обсуждаются в научных исследованиях и являются объектами научного анализа. Однако однозначных трактовок указанных понятий не существует. В экономической литературе выделяют различные подходы к их определению (табл. 1).

Таблица 1

\section{Определения эконолической категории «инвестиционный клилат»}

\begin{tabular}{|c|c|}
\hline Источник & Определение категории \\
\hline $\begin{array}{l}\text { Рейтинговое } \\
\text { агентство «Экс- } \\
\text { перт-РА» }\end{array}$ & $\begin{array}{l}\text { Инвестиционный климат включает объективные возможности страны или } \\
\text { региона (инвестиционный потенциал) и условия деятельности инвестора } \\
\text { (инвестиционный риск)* }\end{array}$ \\
\hline $\begin{array}{l}\text { А. Ю.Андрианов } \\
\text { С. В .Валдайцев } \\
\text { П. В.Воробьев }\end{array}$ & $\begin{array}{l}\text { Инвестиционный климат - степень благоприятности для потенциальных } \\
\text { инвестиций в данный момент времени на рассматриваемой территории (на- } \\
\text { пример, в стране). Инвестиционный климат фиксируется по ряду факторов, } \\
\text { характеризующих для разных инвесторов привлекательность инвестирова- } \\
\text { ния в соотношении риска и доходности }[1, \text { с. } 74]\end{array}$ \\
\hline К. В. Балдина & $\begin{array}{l}\text { Инвестиционный климат - совокупность политических, экономических, } \\
\text { юридических, социальных, бытовых, климатических, природных, инфра- } \\
\text { структурных и других факторов, которые предопределяют степень риска } \\
\text { капиталовложений и возможность их эффективного использования [2, с. 52] }\end{array}$ \\
\hline А. Г. Грязнова & $\begin{array}{l}\text { Инвестиционный климат - это «совокупность сложившихся в какой-либо } \\
\text { стране политических, социально-культурных, финансово-экономических и } \\
\text { правовых условий, определяющих качество предпринимательской инфра- } \\
\text { структуры, эффективность инвестирования и степень возможных рисков } \\
\text { при вложении капитала» [3] }\end{array}$ \\
\hline $\begin{array}{l}\text { И. М. Волков } \\
\text { М. В. Грачева }\end{array}$ & $\begin{array}{l}\text { Инвестиционный климат - совокупность экономических, социальных, по- } \\
\text { литических и культурных условий, обеспечивающих коммерческую привле- } \\
\text { кательность вложений в ту или иную страну или регион [4] }\end{array}$ \\
\hline
\end{tabular}

\section{Baikal Research Journal}

электронный научный журнал Байкальского государственного университета 
Исходя из представленных толкований категории «инвестиционный климат» (см. табл. 1), можно заметить, что данные трактовки имеют как определенные сходства, так и различия. Мнения авторов можно разделить на две группы. Одни авторы рассматривают инвестиционный климат как совокупность факторов, отражающих развитие внутри системы. Определение уровня их развития предоставляет возможность оценить инвестиционный климат хозяйствующего субъекта. Другие авторы рассматривают данную категорию более обширно и включают в определение также влияние факторов риска на различные составляющие элементы развития системы. Риск- это вероятность потери средств, вложенных потенциальным инвестором. Оценка рисков чрезвычайно важна для любого инвестора, особенно для осуществляющего капиталовложения за рубежом, так как он попадает в незнакомую среду, поэтому учет влияния рисков предоставляет возможность более полно раскрыть сущность данной категории, определить и оценить инвестиционный климат субъекта.

Таким образом, «инвестиционный климат» - это обобщенная характеристика совокупности социальных, финансово-экономических, организационных, правовых, политических, культурных условий, предопределяющих привлекательность и целесообразность инвестирования в экономическую систему того или иного уровня хозяйствования (экономику страны, региона, отрасли, предприятия), эффективность инвестирования и степень возможных рисков при вложении капитала.

Рассмотрев представленные трактовки категории «инвестиционная привлекательность» хозяйствующего субъекта (табл. 2), можно сделать вывод, что некоторые авторы отожествляют данное понятие с термином «инвестиционный климат». Однако в теоретико-методологическом плане необходимо разграничивать категории инвестиций и четко понимать сходства и отличия данных определений. Инвестиционный климат определяет уровень развития инвестиционного объекта, оценивает всю совокупность экономических показателей и факторов риска. Инвестиционная привлекательность характеризуется состоянием объекта, его дальнейшим развитием, перспективами доходности и роста $[5$, с. 45]. При оценке инвестиционной привлекательности инвестору целесообразно уделять особое внимание экономическим показателям и факторам риска, с которыми он будет сталкиваться чаще, поэтому уровень инвестиционной привлекательности одного и того же объекта инвестирования может иметь различные значения, исходя из целей и задач вложения инвестиций.

Таким образом, «инвестиционная привлекательность» - это субъективный показатель, который определяет взаимосвязь инвестиционного потенциала (совокупность сложившихся экономических условий, факторов) и инвестиционных рисков (вероятности возникновения потерь, полного или частичного недостижения результатов осуществления инвестиций), обуславливающих потенциальный платежеспособный спрос на инвестиции.

Обобщив представленные определения понятия «инвестиционная активность» (табл. 3), можно сделать вывод, что данная экономическая категория означает развитие и интенсивность инвестиционной деятельности хозяйствующего субъекта, характеризующаяся объемом и темпами привлечения инвестиций в основной капитал. Можно отметить также зависимость динамики инвестиционной активности от форм и источников финансирования инвестиционной деятельности. В качестве основных требований, предъявляемых к источникам финансирования, в том числе активизации инвестиционной деятельности, выступает инвестиционный потенциал. Уровень инвестиционной активности тесно связан с развитием инвестиционного потенциала системы, который характеризуется в том числе рентабельностью собственного капитала и масштабами реинвестирования прибыли. Инвестиционная активность при этом определяется способностью предприятия к реинвестированию прибыли в размере, необходимом для осуществления расширенного воспроизвод-

\section{Baikal Research Journal}

электронный научный журнал Байкальского государственного университета 
ства, с учетом наличия для этого собственных средств и долгосрочных привлеченных средств с целью повышения его организационной устойчивости. Характерной особенностью всех приведенных трактовок понятия «инвестиционной активности» является отождествление ее с совокупностью действий, обусловленных движением объемов инвестиционных вложений.

Таблица 2

Определения эконолической категории «инвестиционная привлекательность»

\begin{tabular}{|c|c|}
\hline Источник & Определение категории \\
\hline $\begin{array}{l}\text { Рейтинговое } \\
\text { агентство «Экс- } \\
\text { перт-РА» }\end{array}$ & $\begin{array}{l}\text { Инвестиционная привлекательность регионов определяется по двум ин- } \\
\text { тегральным показателям: интегральному инвестиционному потенциалу и } \\
\text { интегральному инвестиционному риску* }\end{array}$ \\
\hline $\begin{array}{l}\text { И. В. Гришина } \\
\text { А. Г. Шахназаров } \\
\text { И. И. Ройзман }\end{array}$ & $\begin{array}{l}\text { Инвестиционная привлекательность - система или сочетание различных } \\
\text { объективных признаков, средств, возможностей, обуславливающих в сово- } \\
\text { купности потенциальный платежеспособный спрос на инвестиции в страну, } \\
\text { регион, отрасль, предприятие [6] }\end{array}$ \\
\hline $\begin{array}{l}\text { Л. С. Гиляров- } \\
\text { ская }\end{array}$ & $\begin{array}{l}\text { Инвестиционная привлекательность - оценка эффективности использо- } \\
\text { вания собственного и заемного капитала, анализ платежеспособности и } \\
\text { ликвидности предприятия [7] }\end{array}$ \\
\hline Е. Р. Орлова & $\begin{array}{l}\text { Инвестиционная привлекательность региона представляет собой объек- } \\
\text { тивные предпосылки для инвестирования и количественно выражается в } \\
\text { объеме капитальных вложений, которые могут быть привлечены в регион } \\
\text { исходя из присущих ему инвестиционного потенциала и уровня некоммер- } \\
\text { ческих рисков [8, с. 28] }\end{array}$ \\
\hline $\begin{array}{l}\text { Д. А. Ендовицкий } \\
\text { В. А. Бабушкин } \\
\text { Н. А. Батурина }\end{array}$ & $\begin{array}{l}\text { Инвестиционная привлекательность - совокупность взаимосвязанных } \\
\text { между собой характеристик экономического потенциала, доходности } \\
\text { операций с активами и инвестиционного риска хозяйствующего субъек- } \\
\text { та, обладащего определенной способностью к устойчивому развитию в } \\
\text { условиях конкурентной среды и отвечающего допущению о непрерывности } \\
\text { деятельности [9] }\end{array}$ \\
\hline
\end{tabular}

* URL : http://www.raexpert.ru/ratings/regions/2015/method/.

Таблица 3

Определения экономической категории «инвестиционная активность»

\begin{tabular}{|l|l|}
\hline \multicolumn{1}{|c|}{ Источник } & \multicolumn{1}{|c|}{ Определение категории } \\
\hline В. В. Крамин & $\begin{array}{l}\text { Инвестиционная активность - реальное развитие инвестиционной дея- } \\
\text { тельности в виде инвестиций в основной капитал [10] }\end{array}$ \\
\hline $\begin{array}{l}\text { И. В. Гришина } \\
\text { И. И. Ройзманаров }\end{array}$ & $\begin{array}{l}\text { Инвестиционную активность как развитие и интенсивность инвестицион- } \\
\text { инвестиций в основной капитал региона [11, с.10] }\end{array}$ \\
\hline Д. Б. Крутских & $\begin{array}{l}\text { Инвестиционная активность региона выступает как объективная харак- } \\
\text { теристика, присущая конкретной территории страны и изеняемая под } \\
\text { влиянием множества факторов, действующих на макро-, мезо- и микро- } \\
\text { экономическом уровнях. Названные детерминанты инвестиционной ак- } \\
\text { тивности имеют разную природу: экономическую, социальную, институ- } \\
\text { циональную [12] }\end{array}$ \\
\hline $\begin{array}{l}\text { Т. Н. Егорова } \\
\text { С. В. Шманёв }\end{array}$ & $\begin{array}{l}\text { Инвестиционная активность - характеристика интенсивности инвести- } \\
\text { ций, которая может быть определена на основе соотношения текущего } \\
\text { объема инвестированных средств к предыдущему [13, с.17]. }\end{array}$ \\
\hline $\begin{array}{l}\text { С. П. Бараненко } \\
\text { К. Д. Бусыгин }\end{array}$ & $\begin{array}{l}\text { Инвестиционная активность макроэкономического уровня представля- } \\
\text { ет собой «характеристику состояния инвестиционной деятельности всей } \\
\text { совокупности хозяйствующих субъектов во всех секторах национальной } \\
\text { экономики, направленную на обеспечение расширенного воспроизвод- } \\
\text { ства», «отражение интенсивности привлечения и перераспределения инве- } \\
\text { стиционных ресурсов, направляемых в обеспечение устойчивого развития } \\
\text { национальной (региональной, отраслевой) экономики» [14, с. 138] }\end{array}$ \\
\hline
\end{tabular}

\section{Baikal Research Journal}


Таким образом, рассмотренные определения экономических категорий «инвестиционный климат», «инвестиционная привлекательность» и «инвестиционная активность» позволяют сделать вывод, что одним из обобщающих показателей, определяющих их итоговое значение, выступает категория «инвестиционный потенциал». Однако понятие «инвестиционный потенциал» также не имеет единого терминологического содержания (табл. 4).

Таблица 4

Определения экономической категории «инвестищионный потенщиал»

\begin{tabular}{|c|c|}
\hline Источник & Определение категории \\
\hline $\begin{array}{l}\text { Рейтинговое } \\
\text { агентство «Экс- } \\
\text { перт-РА» }\end{array}$ & $\begin{array}{l}\text { Инвестиционный потенциал (инвестиционная емкость территории) скла- } \\
\text { дывается как сумма объективных предпосылок для инвестиций, зави- } \\
\text { сящая как от наличия и разнообразия сфер и объектов инвестирования, } \\
\text { так и от их экономического «здоровья». Потенциал страны или региона } \\
\text { в своей основе характеристика количественная, учитывающая основные } \\
\text { макроэкономические показатели, насыщенность территории факторами } \\
\text { производства (природными ресурсами, рабочей силой, основными фонда- } \\
\text { ми, инфраструктурой и т. п.), потребительский спрос населения и др.* }\end{array}$ \\
\hline С. Г. Сериков & $\begin{array}{l}\text { Инвестиционный потенциал складывается в виде суммирования объектив- } \\
\text { ных предпосылок для инвестиций, зависящий как от разнообразия сфер и } \\
\text { объектов инвестирования, так и от их экономического «здоровья» [15, с. } 222]\end{array}$ \\
\hline $\begin{array}{l}\text { Л. А.Сипко } \\
\text { О. А. Беляков }\end{array}$ & $\begin{array}{l}\text { Инвестиционный потенциал как возможность предприятия инвестировать } \\
\text { в свое собственное развитие, покупая различные активы и создавая допол- } \\
\text { нительные финансовые потоки [16] }\end{array}$ \\
\hline О. Ф. Семыкина & $\begin{array}{l}\text { Инвестиционный потенциал как совокупность ресурсов, свойств и особен- } \\
\text { ностей, обеспечивающих рост доходности капитала и конкурентоспособно- } \\
\text { сти предприятия в долгосрочной перспективе [17] }\end{array}$ \\
\hline $\begin{array}{l}\text { А. М. Марголина } \\
\text { А. Я. Быстрякова }\end{array}$ & $\begin{array}{l}\text { Инвестиционный потенциал представляет собой не простую, а определен- } \\
\text { ным образом упорядоченную совокупность инвестиционных ресурсов, по- } \\
\text { зволяющую добиться эффекта синергизма при их использовании, а также } \\
\text { целесообразность расширения совокупности материальных, финансовых и } \\
\text { интеллектуальных ресурсов, традиционно учитываемых при формирова- } \\
\text { нии инвестиционного потенциала, включая в нее такие виды ресурсов, как } \\
\text { природные и информационные [18; } 19]\end{array}$ \\
\hline Л. А. Толстолесова & $\begin{array}{l}\text { Инвестиционный потенциал - потенциальная возможность, позволяю- } \\
\text { щая аккумулировать необходимый объем финансово- инвестиционных } \\
\text { ресурсов для осуществления инвестиционной деятельности [20, с. } 224]\end{array}$ \\
\hline
\end{tabular}

Обобщая перечисленные точки зрения, можно заметить, что мнения авторов при толковании данного понятия можно разделить на две категории. Одни авторы определяют инвестиционный потенциал как совокупность имеющихся ресурсов хозяйствующего субъекта, другие авторы трактуют понятие как потенциальную возможность хозяйствующего субъекта к осуществлению инвестиционной деятельности. Данные определения верно отражают сущность категории, однако и те и другие авторы не полностью раскрывают всю ее суть. Необходимо поэтому сформулировать наиболее точное и полное определение категории «инвестиционный потенциал", которое должно объединять как характеристики наличия ресурсов, так и характеристики возможностей субъектов.

Итак, инвестиционный потенциал - это способность хозяйствующего субъекта к рациональному и эффективному управлению и использованию всех имеющихся в его распоряжении экономических ресурсов (собственных и заемных) для реализации инвестиционных возможностей в целях обеспечения удовлетворения материальных, финансовых и интеллектуальных потребностей воспроизводства капитала.

Значения инвестиционного климата, инвестиционной привлекательности и инвестиционной активности любого хозяйствующего субъекта находятся в пря-

\section{Baikal Research Journal}

электронный научный журнал Байкальского государственного университета 
мой зависимости от значения их инвестиционного потенциала [19, с. 9]. Чем выше инвестиционный потенциал, тем благоприятнее инвестиционный климат экономической системы. Данная система более привлекательна для инвестора, что соответственно повышает интенсивность инвестиционной деятельности, характеризующую инвестиционную активность хозяйствующего субъекта.

На основании проведенного анализа экономической сущности основных категорий инвестиций, можно сделать вывод, что инвестиционный потенциал хозяйствующего субъекта является базовой характеристикой при оценке и выборе инвестором потенциальных объектов инвестирования. Определение значения данного показателя позволит выявить перспективы развития оцениваемой экономической системы, а также спрогнозировать эффективность вложения ресурсов [21, с. 34]. Таким образом, проведение грамотной инвестиционной политики предполагает управление инвестиционными параметрами экономического развития, ключевым из которых является инвестиционный потенциал.

Можно отметить, что инвестиционному потенциалу хозяйствующего субъекта присущи следующие характерные особенности:

- инвестиционный потенциал может быть охарактеризован в рамках дуалистического подхода - с одной стороны, как совокупность имеющихся ресурсов хозяйствующего субъекта, с другой, как потенциальная возможность хозяйствующего субъекта к осуществлению инвестиционной деятельности;

- значения инвестиционного климата и инвестиционной привлекательности любого хозяйствующего субъекта находятся в прямой зависимости от значения их инвестиционного потенциала. Чем выше инвестиционный потенциал, тем благоприятнее инвестиционный климат хозяйствующей системы и, соответственно, данная система более привлекательна для инвестора как объект вложения инвестиций;

- величина инвестиционного потенциала хозяйствующего субъекта зависит от наличия различных видов ресурсов, которыми он располагает. Однако степень использования ресурсов влияет на уровень реализации потенциала, а рациональное и эффективное управление ресурсами позволяет значительно увеличить значение итогового показателя;

- инвестиционный потенциал каждого отдельного хозяйствующего субъекта имеет свою специфику, так как для различных объектов инвестирования определенный фактор может оказывать влияние с различной степенью силы, поэтому для объективной оценки данной категории инвестиций необходим дифференцированный подход к определению величины итогового показателя каждого отдельного хозяйствующего субъекта.

\section{Список использованной литературы}

1. Андрианов А. Ю. Инвестиции : учеб. для бакалавров / А. Ю. Андрианов, С. В. Валдайцев, П. В. Воробьев. - М. : Проспект, 2013. - 592 с.

2. Балдина К. В. Системный анализ и управление : учеб. пособие / К. В. Балдина. - М. : Дашков и $\mathrm{K}^{\circ}, 2006 .-288$ с.

3. Грязнова А. Г. Финансово-кредитный энциклопедический словарь / А. Г. Грязнова. М. : Финансы и статистика, 2002. - 1168 с.

4. Волков И.М. Проектный анализ: Продвинутый курс / И.М. Волков, М.В. Грачева. М.: ИНФРА-М, 2004. $-495 \mathrm{c.}$

5. Корчагин Ю. А. Инвестиции и инвестиционный анализ : учеб. пособие / Ю. А. Корчагин, И. П. Маличенко. - Ростов н/Д. : Феникс, 2010. -601 с.

6. Гришина И. В. Комплексная оценка инвестиционной привлекательности и инвестиционной активности российских регионов: методика определения и анализа взаимосвязей / И. В. Гришина, А. Г. Шахназаров, И. И. Ройзман // Инвестиции в России. -2000 . - № 4. C. $13-20$.

\section{Baikal Research Journal}


7. Гиляровская Л. Т. Экономический анализ / Л. Т. Гиляровская. - М.: Юнити-Дана, 2004. $-615 \mathrm{c}$.

8. Орлова Е. Р. Инвестиции: курс лекций / Е. Р. Орлова. - М. : Омега-Л, 2006. — 207 с.

9. Ендовицкий Д. А. Анализ инвестиционной привлекательности организации / Д. А. Ендовицкий, В. А. Бабушкин, Н. А. Батурина. - М. : Кнорус, 2010. - 376 с.

10. Крамин Т. В. Развитие методики управления инвестиционной привлекательностью регионов / Т. В. Крамин / Вестник Астраханского государственного технического университета. - 2012. - № 1. - С. 41-47.

11. Ройзман И. Типология инвестиционного климата регионов на новом этапе развития российской экономики / И. Ройзман, И. Гришина, А. Шахназаров // Инвестиции в России. -2003 . - № 3. - С. 3-15.

12. Крутских Д. Б. Сущность инвестиционной активности региона / Д. Б. Крутских // Вестник Воронежского государственного университета. -2011 . — № 1. - С. 72-76.

13. Егорова Т. Н. Инвестиционная активность предприятий как основа их инновационного развития / Т. Н. Егорова, С. В. Шманёв // Транспортное дело России. —2011. — № 6 . — C. 17-18.

14. Бараненко С. П. Сущность и экономическое содержание понятий «инвестиционная активность» и «инвестиционная привлекательность» / С. П. Бараненко, К. Д. Бусыгин // Актуальные проблемы гуманитарных и естественных наук. - 2015. - № 1. - С. 133-141.

15. Сериков С. Г. Инвестиционный потенциал региона / С. Г. Сериков // Экономика и предпринимательство. - 2015. - № 3-2. - С. 220-225.

16. Сипко Л. А. Инвестиционный потенциал: методология статистической оценки / Л. А. Сипко, О. А. Беляков. - Новосибирск : СибУПК, 2004. - 83 с.

17. Семыкина О. Ф. Факторы увеличения инвестиционной активности предприятия: системный подход / О. Ф. Семыкина // Вестник Томского государственного университета. 2006. - № 292-I. - C. 158-162.

18. Марголин А. М. Экономическая оценка инвестиций / А. М. Марголин, А. Я. Быстряков. - М. : Эксмос, 2001. - 240 с.

19. Бирюкова А. И. Оценка инвестиционной привлекательности промышленного сектора региона : автореф. дис. ... канд. экон. наук : 08.00.05 / А. И. Бирюкова. - Иркутск, 2004. - 25 c.

20. Толстолесова Л. А. Финансово-инвестиционный потенциал сырьевых регионов и стратегия его реализации / Л. А. Толстолесова // Вестник Тюменского государственного университета. - 2011. - № 11. - С. 120-126.

21. Веригин П. А. Основы формирования и оценки инвестиционного потенциала предприятия / П. А. Веригин // Экономический вестник : сб. науч. тр. - М. : Моск. технол. ин-т, 2006. - Вып. 5. - С. 32-35.

\section{References}

1. Andrianov A. Yu., Vorobyev P. V. Investitsii [Investments]. Moscow, Prospekt Publ., 2013. $592 \mathrm{p}$.

2. Baldina K. V. Sistemnyi analiz i upravlenie [System analysis and management]. Moscow, Dashkovi K ${ }^{\circ}$ Publ., 2006. 288 p.

3. Gryaznova A. G. Finansovo-kreditnyi entsiklopedicheskii slovar' [Finance and Credit Encyclopedic Dictionary]. Moscow, Finansy i Statistika Publ., 2002. 1168 p.

4. Volkov I. M., Gracheva M. V. Proektnyi analiz: Prodvinutyi kurs [Project Analysis: An Advanced Course]. Moscow, Infra-M Publ., 2004. 495 p.

5. Korchagin Yu. A., Malichenko I. P. Investitsii $i$ investitsionnyi analiz [Investments and investment analysis]. Rostov-on-Don, Feniks Publ., 2010. 601 p.

6. Grishina I. V., Shakhnazarov A. G., Roizman I. I. Comprehensive assessment of investment attractiveness and investment performance of Russian regions: methods of definition and analysis of interrelations. Investitsii $v$ Rossii = Investments in Russia, 2000, no. 4, pp. 13-20. (In Russian).

7. Gilyarovskaya L. T. Ekonomicheskii analiz [Economic analysis]. Moscow, Yuniti-Dana Publ., 2004. 615 p.

8. Orlova E. R. Investitsii: kurs lektsii [Investments: a Course of Lectures]. Moscow, Omega-L Publ., 2006. 207 p.

\section{Baikal Research Journal}


9. Endovitsky D. A., Babushkin V. A., Baturina N. A. Analiz investitsionnoi privlekatel'nosti organizatsii [Analysis of a company's investment attractiveness]. Moscow, Knorus Publ., 2010. $376 \mathrm{p}$.

10. Kramin T. V. Development of management methods for regional investment attractiveness Vestnik Astrakhanskogo gosudarstvennogo tekhnicheskogo universiteta = Bulletin of Astrakhan State Technical University, 2012, no. 1, pp. 41-47. (In Russian).

11. Roizman I., Grishina I., Shakhnazarov A. Typology of regions' investment climate at the new stage of developing Russian economy. Investitsii v Rossii=Investments in Russia, 2003, no. 3, pp. 3-15. (In Russian).

12. Krutskikh D. B. Essence of regional investment performance. Vestnik Voronezhskogo gosudarstvennogo universiteta. $=$ Proceedings of Voronezh State University, 2011, no. 1, pp. 72-76. (In Russian).

13. Egorova T. N., Shmanev S. V. Investment activity of the enterprises as a basis of their innovative development. Transportnoe delo Rossii = Transport Business of Russia, 2011, no. 6, pp. 17-18. (In Russian).

14. Baranenko S. P., Busygin K. D. Essence and economic content of concepts «investment performance» and «investment attractiveness» ktual'nye problemy gumanitarnykh i estestvennykh nauk = Topical problems in Humanities and Natural Sciences, 2015, no. 1, pp. 133-141. (In Russian).

15. Serikov S. G. Investment potential of the region. Ekonomika i predprinimatel'stvo $=$ Economics and Entrepreneurship, 2015, no. 3-2, pp. 220-225. (In Russian).

16. Sipko L. A., Belyakov O. A. Investitsionnyi potentsial: metodologiya statisticheskoi otsenki [Investment potential: methodology of statistic assessment]. Novosibirsk, SibUPK Publ., 2004. 83 p.

17. Semykina O. F. Factors of increasing company's investment performance: system analysis. Vestnik Tomskogo gosudarstvennogo universiteta $=$ Tomsk State University Journal, 2006, no. 292-I, pp. 158-162. (In Russian).

18. Margolin A. M., Bystryakov A. Ya. Ekonomicheskaya otsenka investitsii [Economic assessment of investments]. Moscow, Eksmos Publ., 2001. 240 p.

19. Biryukova A. I. Otsenka investitsionnoi privlekatel'nosti promyshlennogo sektora regio na. Avtoref. Kand. Diss. [Assessing investment attractiveness of regional industrial sector. Cand. Diss. Thesis]. Irkutsk, 2004. 25 p.

20. Tolstolesova L. A. Finance-investment potential of raw materials regions and strategy of its realization. Vestnik Tyumenskogo gosudarstvennogo universiteta. Sotsial'no-ekonomicheskie i pravovye issledovaniya = UT Research Journal. Socio-Economic and Legal Research, 2011, no. 11, pp. 120-126. (In Russian).

21. Verigin P. A. Basics of developing and assessing a company's investment potential. Ekonomicheskii vestnik [Economic Bulletin]. Moscow Technological Institute Publ., 2006, iss. 5, pp. 32-35. (In Russian).

\section{Информация об авторе}

Новикова Ирина Юрьевна - аспирант, кафедра экономики и управления бизнесом, Байкальский государственный университет, 664003, г. Иркутск, ул. Ленина, 11, e-mail: arinkachka18@mail.ru.

\section{Author}

Irina Yu. Novikova - PhD Student, Department of Economics and Business Administration, Baikal State University, 11 Lenin St., 664003, Irkutsk, Russian Federation, e-mail: arinkachka18@mail.ru.

\section{Библиографическое описание статьи}

Новикова И. Ю. Инвестиционный потенциал хозяйствующего субъекта в системе основных категорий инвестиций / И. Ю. Новикова // Baikal Research Journal. - 2016. - Т. 7, № 5. - DOI : 10.17150/2411-6262.2016.7(5).11.

\section{Reference to article}

Novikova I. Yu. Investment potential of the entity in the system of main categories of investments. Baikal Research Journal, 2016, vol. 7, no. 5. DOI : 10.17150/2411-6262.2016.7(5).11. (In Russian).

\section{Baikal Research Journal}

